\title{
Decimal Number System: Knowledge of Quebec Students Educated under the 2001 and 1981 Programs and Teaching Situations
}

\author{
Jeanne Koudogbo \\ University of Sherbrooke, Québec, Canada
}

Decimal Number System (DNS) is fundamental in the teaching of arithmetic. Although several scholars have studied the system, it was mostly the studies carried out in the 80s-90s that brought out its complexity and also the difficulties students encounter with its learning. In some of them, the scholars saw the students' difficulties through the prism of the earlier program's behaviourist and objective foundation structure. However, the current curriculum in Quebec, based on social constructivism and structured according to competences is a departure from the past. In this context, this study, inspired by a doctoral dissertation, is intended to explore the strategies and knowledge in solving tasks on the DNS of 154 third grade students from six schools as well as teaching situations in two classes, more than 30 years after the studies were carried out in Quebec. The main data collected for the study included audio interviews with 18 students, a questionnaire $(n=154)$, videotape of lessons and documentation. First, we outlined the strategies and knowledge of pupils on the DNS as well as teaching situations, and then we compared them with earlier studies as well as the current program's competence-based structuring. We also discussed the scope of the task and class effects. We used the DNS frame of reference and the Theory of didactical situations for the analyses.

Keywords: Mathematics learning and teaching, student's understanding and knowledge, decimal number system, curriculum, elementary education.

The Decimal Number System (DNS) or base 10 positional number system is emblematic in the teaching and learning of arithmetic in elementary school. As such, it has been studied by scholars of mathematics education all over the world (Bednarz \& Janvier, 1982; 1984a; 1984b; 1986; 1988; Brun, Giossi \& Henriques, 1984; Deblois, 1993; Fuson, 1988; Kamii \& Baker Housman, 2000; Koudogbo-Adihou, 2001; Koudogbo, 2013, 2015; Tempier, 2013), and more specifically in the two decades of 1980 to 2000. The studies carried out during the implementation of the program in terms of objectives (1980 to 2001), laid bare the complexity of the DNS, and identified students' difficulties and incorrect and false conceptions. Bednarz and Janvier (1982; 1984a; 1986) in particular, carried out diagnostic studies by presenting tasks to 
primary school students to identify their strategies, conceptions and difficulties, followed by longitudinal studies from 1980 to 1983, based on a constructivist frame of reference, with well-planned mathematical situations conducive to learning the concept (Bednarz \& Janvier, 1984b; 1988). They aimed at helping students to build a meaningful and significant understanding of numeration and DNS. These authors, like other scholars (Deblois, 1993; Kamii \& Baker Housman, 2000), interpreted these difficulties and conceptions as the effects of the objectives-based program that was in effect at that time. The efficiency of the teaching methods and even the structuring of the program itself, were called into question because they did not focus enough on the process of knowledge acquisition by the students, especially the necessary coordination between numbers-numeration-DNS, and working on numbers (Bednarz \& Janvier, 1986).

In fact, the program introduced a sequential order numeration structure of numbers in terms of complexity. Thus, numbers less than 69 were studied in the $1^{\text {st }}$ year, less than 99 in the $2^{\text {nd }}$ year, and less than 199 in the $3^{\text {rd }}$ year... However, it is while learning the higher numbers that the students' difficulties become apparent. Moreover, the analysis done by Bednarz and Janvier (1982; 1984a; 1986) of the proposed situations in the textbooks in Quebec, Canada, of this period shows a disconnect between numbers and operations.

In the early 2000s, in Quebec, as well as in many Western countries, there was educational reform. In place since 2001, the guidelines in the Quebec Education Program (Government of Quebec [GQ], 2001) is a major departure from the previous program. Whereas the 1981 program is based on a behaviorist learning theory and is structured in terms of overall and intermediate objectives, the 2001 program is based on social constructivism. The constructivism underlying this paradigm puts more "emphasis on skills development and output profiles rather than on the specification of numerous and fragmented objectives" (Legendre, 2004, p. 86). In this context, learning is a process favored by situations which represent a real challenge for the student and which involve a questioning of his knowledge and his representations (GQ, 2006). In addition, the organization of "essential knowledges" (pp. 150-152) shows a more integrated perspective of teaching and learning number system (and the DNS) compared to the previous program.

Thus, this program opts instead for a structuring in terms of competence and complex skills. This shift brought many changes. To enable the development of mathematical competencies, this program requires the implementation of mathematical situations of a certain complexity, i.e., situations that are different from exercises and which treatment calls for an organization and a coordination of new knowledge. For example, a structuring of the DNS teaching contents places this knowledge among the essential knowledge linked to the arithmetic of the "domain of mathematics, science and technology" (GQ, 2001, pp. 143-177). The preferred contents and their breakdown show a certain connection between numbers, counting, DNS, and 

is reflected in the numbers operations and enables groupings: doing groupings (used in the addition), or undoing groupings, with the borrowing used in the subtraction. Another principle is the decimal place value, in which each digit in a number refers to a number less than the base. The position of the digit in the number gives its value, its weight. So a positional principle also characterizes this system (Tempier, 2010). But many studies revealed that the "positional" principle is mainly worked and taught to the detriment of its articulation with the "decimal" principle. For example, the results of the studies by Tempier (2010) in France reveal that only the "position" aspect is rather considered. In addition the resources offered to teachers are structured to work on the "position" aspect and don't promote a real understanding of the articulation between the principles of the DNS (Kamii, 1990; Tempier, 2010). Thus, if students easily learn to identify each position in a number, it is more difficult to grasp the value of a digit according to the position (Brun, Giossi, \& Henriques, 1984), and mainly the value of a group of digits in a number (Kamii \& Baker Housman, 2000; Perret, 1985; Tempier, 2010; 2013).

The DNS also takes on some of the roles of designation or representation of numbers (Ifrah, 1996), computation of collections/quantity of operations and recognition of certain properties of numbers. In addition, the DNS includes additive and multiplicative characteristics. Conceptually, the multiplicative structure has two interpretations: repeated addition, where a number of groupings can be repeated many times and an idea of exponentiation, i.e., the groupings of groupings. The coordination of these two interpretations is, for students, a very difficult task. These different elements account for the complexity of the concept and some interlocking multiple dimensions, as several studies have also shown empirically (Bednarz \& Janvier, 1982; 1984a; 1986; Deblois, 1993; Fuson, 1988) in addition to the difficulties they raise for students. In fact, a lack of articulation of these multiple dimensions of DNS reinforced difficulties and false conceptions. It is important to present the studies of Bednarz and Janvier (1982; 1984a; 1984b; 1986; 1988) for two reasons: a) they pointed out these difficulties and misconceptions; b) they constitute the basis of this research. The authors carried out two studies during 1979-80 and during 1980-83. Their first diagnostic study on the treatment of collections and the meaning of actions on them was carried out with 40 students in grade 1 (6-7 years), 75 pupils (group A) in grade 3 (8-9 year) and 45 in grade 4 (9-10 years) and permitted to characterize students' inappropriate conceptions of the DNS. These conceptions could be explained by the structuring of the objectives based program which favors the fragmentation of teaching content and fragmented learning organized around reading, writing and representation of numbers. According to them, the rules of using material illustrate the conventional order of written symbolism. This favors a representation of the writing of the number as an alignment or juxtaposition of digits, not in terms of groupings and associated place values (Bednarz \& Janvier, 1982; 1984a; 1986). 


does the teacher decree it based on the skills underlying the situation or through knowing and knowledge?

\section{Methods}

\section{Research Method Design, Site and Participants}

A mixed method (Johnson \& Onwuegbuzie, 2004) made it possible to respond to the three research objectives, combining qualitative and quantitative methods (frequencies and percentages, nonparametric tests). Data was collected through non-probabilistic and intentional sample (Patton, 2002) since it was carried out according to its quality to document the research question and help to the understanding of the research subject. In addition the tests used for the analyses are considered as a support for the interpretation of findings. Consequently, the findings of this research should not be generalized.

The process of participants' selection began with a study of Quebec Education Program in Mathematics and Progressing of Learning in Elementary School (GQ, 2001), followed by a study of approved textbooks and instructional materials and previous research findings on DNS (Bednarz \& Janvier, 1982; 1984a; 1984b; 1988). Subsequently, the grade 3 was chosen and the schools located in Quebec were considered due to feasibility. After discussion with school boards and heads of schools, invitations to participate were sent to targeted teachers. We then discussed about the components of the study, negotiated with interested teachers $(N=14)$ and chose those who were truly interested in contributing $(N=8)$. Finally, we planned and collected data during the 2009-2010 school year.

More particularly, participants of the study (see Table 1) came from three regions and school boards in Quebec. They are composed of 154 students from third grade (aged 8-9) and from eight classes (group D). They were recruited in order to obtain a varied portrait of students' strategies and knowledge. The inclusion criteria are the grade 3 to which the subjects in preceding studies (Bednarz \& Janvier, 1982; 1984b; 1988) belonged to and the essential knowledge aimed at in the 3rd year as per the DNS. In addition, two classes (RH and RJ) among the eight were involved in the videotape of their teaching situations. Besides, as the studies of Bednarz and Janvier constitute the reference of the current study (in response to objective 1) the different groups of students (grade 3) who participated to their researches will be also considered (groups A, B1 and B3).

\section{Data Collection and Data Analysis}

Three complimentary data collection methods were used. First, individual audio interviews of duration of 15 minutes were done with a limited number of 18 students (identified by their teacher) belonging to three different schools of the same school board (group C, derived from group D).

The interviews aimed to describe their strategies and knowing or knowledge in solving the two tasks taken from the studies of Bednarz and Janvier $(1982 ; 1984 b ; 1988)$ in order to compare them against their results 


(another student) our number system. In class RH, students are asked to respond to exercises dealing with the DNS positional principle.

Figure 3. Written questionnaire.

The process of analyzing the interview data helps to bring out the underlying reasoning to the students' strategies and the knowledge they are based on. The analyses were made from the strategies of students previously identified in the studies of Bednarz and Janvier (1982;1984b;1988). For the task 1 (enumeration of 144 rods), there are two categories of strategies: 1) the coding of collections, with the use of groupings in order to write a code linked with them or the use of grouping of groupings. 2) The coding of collection of items, which is the grouping in order to count, the counting one by one and the estimation. For task 2 (solving problem), there are also two categories of strategies: 1) the use of the rule of grouping with the collection strategy (association of a number to each grouping and computation), the groupings strategy (proceeding from the picture and mental computation by unmaking grouping) and whatever the strategy (a confusion on groupings/impossibility to operate on them). 2) No use of the rule of grouping with the impossibility to solve the problem or partially/locally. Descriptive statistical analysis (frequencies and percentages) helped to establish a comparison between the strategies used by students in our study and Bednarz and Janvier's studies $(1982 ; 1984 b ; 1988)$.

The analysis of the data from the questionnaire was carried out from the conceptual analysis of the DNS as well as the conceptual tools of the TDS, 

the coding of a collection of items (see Table 2), especially counting one by one. But those who received three years' instruction prepared by the scholars based on a social constructivist approach (group B1) mostly have recourse to the coding of a classified collection (92\%), like the grouping of groupings, of which they are almost the sole users.

Table 2

Task 1-Results of group C versus groups A, B1 and B2

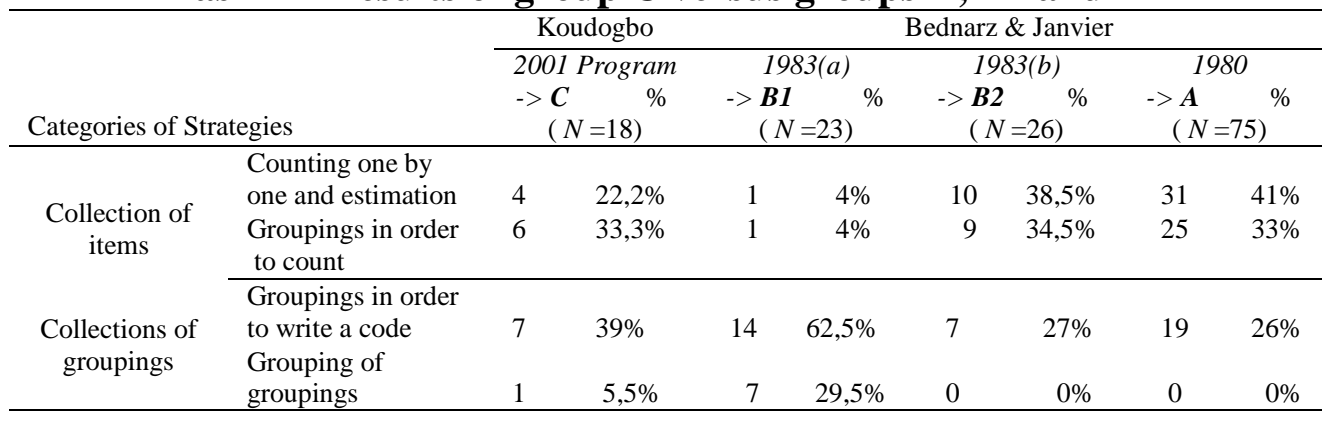

In resolving the second task - problem of peppermints (see Figure 2), group C (78\%) as well as groups A (70\%) and B2 (46\%) have recourse to nongrouping strategies or confuse it with the instructions, contrary to group B1 (8\%), which instead exercises control over the groupings, dismantling them so they could work (see Table 3).

Table 3

Task 2-Results of group C versus groups A, B1 and B2

\begin{tabular}{|c|c|c|c|c|c|c|c|c|c|}
\hline \multirow[b]{3}{*}{$\begin{array}{l}\text { Use Rule of } \\
\text { grouping }\end{array}$} & \multirow[b]{3}{*}{$\begin{array}{c}\text { Categories of } \\
\text { Strategies }\end{array}$} & \multirow{2}{*}{\multicolumn{2}{|c|}{$\begin{array}{c}\text { Koudogbo } \\
2001 \text { Program }\end{array}$}} & \multicolumn{6}{|c|}{ Bednarz \& Janvier } \\
\hline & & & & \multicolumn{2}{|c|}{ 1983(a) } & \multicolumn{2}{|c|}{$1983(b)$} & \multicolumn{2}{|c|}{1980} \\
\hline & & $(N=18)$ & $=18)^{\%}$ & \multicolumn{2}{|c|}{$(N=23)$} & \multicolumn{2}{|c|}{$\begin{array}{l}->\boldsymbol{B 2} \\
\quad(N=26)\end{array}$} & \multicolumn{2}{|c|}{$\stackrel{->}{A}{ }_{(N=75)}^{0}$} \\
\hline No & $\begin{array}{l}\text { Impossibility } \\
\text { to solve }\end{array}$ & 8 & $44,5 \%$ & 1 & $4 \%$ & 8 & $30,5 \%$ & 45 & $60 \%$ \\
\hline \multirow[t]{3}{*}{ Yes } & $\begin{array}{l}\text { Collection } \\
\text { strategy }\end{array}$ & 4 & $22,2 \%$ & 0 & $0 \%$ & 4 & $15 \%$ & 13 & $17 \%$ \\
\hline & strategy & 0 & $0 \%$ & 21 & $92 \%$ & 10 & $39 \%$ & 10 & $13 \%$ \\
\hline & strategy & 6 & $33,3 \%$ & 1 & $4 \%$ & 4 & $15,5 \%$ & 7 & $10 \%$ \\
\hline
\end{tabular}

\section{Knowledge of Students of the 2001 Program in Solving the Tasks of Koudogbo questionnaire (2013)}

Regarding the second objective which is to define students' knowledge concerning the DNS from the responses to the questionnaire (see Figure 3), it was helpful to constitute five performance profiles of all the people and to subsequently distinguish types of useful knowing (knowledge), or the inefficiency mobilized by the students, especially the degrees of inherent mastery of different performances. 


number system. All these considerations seem not to be the case for the teachers involved in our study.

Again, in light of the results from the questionnaire of 154 students (objective 2), it is possible to see that the knowledge of the people studied seems satisfactory. But although the tasks we proposed to the group $\mathrm{C}$ considered the multiple dimensions of DNS, they are mostly structured in terms of questions/answers rather than in terms of solving complex problems. So these results apparently contradict those obtained from the interview of the 18 students on the resolution of problem (task 2) formally used in the studies of Bednarz and Janvier $(1982 ; 1984 b ; 1988)$. In fact solving this problem was very difficult for them and therefore because of the task effect was. It is possible to suggest the current curriculum did not, therefore, modify the students' knowledge.

On the other hand, analyzing the performance profile of students made it possible to highlight, according to a given profile, what the student knows, i.e. his knowledge, or what he knows more or less, or does not know, i.e. his inefficient knowledge (Koudogbo, 2013; 2015) as well as the existing (or nonexisting) links in the knowledge/knowing he mobilizes. For example, if the student recognizes the use of knowledge, he could invoke that in controlling the situation and succeed at a task in an intra-task manner or at the whole task, i.e. in an inter-task manner. The opposite is also true.

The emergence of phenomena such as the class effect and the task effect has a certain scope. Indeed, although statistical analyses do not permit the location of the classes for which the difference is significant, it shows, on the contrary the students' performance in relation to the class to which they belong. The data analyzed come mostly from the responses to the closed questions questionnaire. There is therefore little information that would allow an interpretation of the class effect. However, the analysis of the procedures used by the 18 students who also participated in the audio interviews (group C) provides indications, which help, especially during problem solving, to distinguish mathematical practices peculiar to the classes from which the students come, and it is due to the observations that took place in their own classes. The students' problem-solving procedures, reasoning, strategies, the tools used (design, mathematical writing), and the students' verbalization are elements that distinguish the conduct of students according to the class they belong to. It was possible to formulate the hypothesis according to which the class effects stem from the mathematical culture of the class.

From the above, the hypothesis that several factors interact to determine student performance in a task was formulated. Among those factors, there is the student's performance profile, mathematical culture developed in the class he belongs to (class effect), i.e., the students' way of doing mathematics (Conne, 1999), and the level of the mathematical difficulty of the task (the task effect) with regard to the educational level and knowledge of the student. In light of this, the level of difficulty of a mathematical task depends not only on the 


Johnson, R. B., \& Onwuegbuzie, A. J. (2004). Mixed methods research: A research paradigm whose time has come. Educational Researcher, 33(7), 14-26.

Kamii, C., \& Baker Housman, L. (2000). Young children continue to reinvent arithmetic. Implications of Piaget's theory ( $2^{\text {nd }}$ Ed.). New York, NY: Teachers College Press.

Koudogbo, J. (2013). Portrait actuel des connaissances d'élèves de troisième année de l'ordre primaire et de situations d'enseignement sur la numération de position décimale. Thèse de doctorat, Université du Québec à Montréal, Québec, Canada.

Koudogbo, J. (2015). Vers une approche systémique pour caractériser les performances d'élèves à des tâches sur la numération de position décimale. Actes Groupe de didactique des mathématiques du Québec (GDM) 2015, Sherbrooke : Université de Sherbrooke, 20 au 22 mai, p. 130-144.

Koudogbo Adihou, J. (2001). Approche du "didactique familial" à travers l'étude des mécanismes topogénétiques et chronogénétiques : deux études de cas. Mémoire de maîtrise, Université de Genève, Suisse.

Legendre, M. F. (2004). Approches constructivistes et nouvelles orientations curriculaires: d'un curriculum fondé sur l'approche par objectifs à un curriculum axé sur le développement de compétences. In P. Jonnaert \& D. Masciotra (Dir.), Constructivisme : Choix contemporains. Hommage à Ernst von Glasersfeld (pp. 53-91). Québec, Canada: Presses de l'Université du Québec.

Miura, I. T., Okamoto, Y., Kim, C. C., Steere, M., \& Fayol, M. (1993). First graders' cognitive representation of number and understanding of place value: Cross-national comparisons- France, Japan, Korea, Sweden and the United States. Journal of Educational Psychology, 85(1), 24-30.

Patton, M. Q. (2002). Qualitative research \& evaluation methods. Thousand Oaks, CA: Sage.

Salin, M. H. (2002). Les pratiques ostensives dans l'enseignement des mathématiques comme objet d'analyse du travail du professeur. In O. Venturini, C. Amade Escot \& A. Terrisse (Éds), Étude des pratiques effectives : l'approche des didactiques (pp. 71 -83). Grenoble, France: La Pensée Sauvage.

Somers, R. H. (1962). A new asymmetric measure of association for ordinal variables. American Sociological Review, 27, 799-811.

Tempier, F. (2010). Une étude des programmes et manuels sur la numération décimale au CE2. Grand N, 86, 59-90.

Tempier, F. (2013). La numération décimale de position à l'école primaire. Une ingénierie didactique pour le développement d'une ressource. Thèse de doctorat, Université Paris-Diderot - Paris VII, France. 
